\title{
The Flesh Fly Sarcophaga (Liopygia) crassipalpis Macquart 1839 as an Invader of a Corpse in Calabria (Southern Italy)
}

\author{
Bonacci $\mathrm{T}^{* 1}$, Greco $\mathrm{S}^{1}$, Cavalcanti $\mathrm{B}^{2}$, Brandmayr $\mathrm{P}^{1}$ and Vercillo $\mathrm{V}^{2}$ \\ ${ }^{1}$ Department DiBEST, University of Calabria, 87036 - Rende (CS), Italy \\ ${ }^{2}$ Azienda Sanitaria Provinciale di Cosenza, Sezione di Medicina Legale, 87100 - Cosenza, Italy
}

*Corresponding author: Bonacci T, Department DiBEST, University of Calabria, 87036 - Rende (CS), Italy, E-mail: teresa.bonacci@unical.it

Citation: Bonacci T, Greco S, Cavalcanti B, Brandmayr P, Vercillo V (2014) The Flesh Fly Sarcophaga (Liopygia) crassipalpis Macquart 1839 as an Invader of a Corpse in Calabria (Southern Italy). J Forensic Sci Criminol 2(1): 104. doi: 10.15744/2348-9804.1.404

Received Date: December 03, 2013 Accepted Date: February 10, 2014 Published Date: February 12, 2014

\begin{abstract}
We present an indoor forensic case that occurred in spring 2013 in Cosenza (southern Italy). The entomological evidence collected at the scene consisted of Calliphoridae (Calliphora vicina, Lucilia sericata), Sarcophagidae (Sarcophaga crassipalpis), Fanniidae (Fannia scalaris) and Muscidae (Hydrotaea ignava). The minimum Post Mortem Interval (mPMI) was calculated by relating the entomological evidence to data available for Diptera species in the area and to our knowledge of the development of flies used as forensic indicators in Calabria. We report $S$. crassipalpis as a corpse invader for the first time in Italy.
\end{abstract}

Keywords: Forensic case; Flies; S. crassipalpis; mPMI; Southern Italy

\section{Introduction}

The first aim of forensic entomology is to help investigators estimate the time of death. Its application has become widespread in many countries because the entomological evidence on corpses (especially Diptera and Coleoptera) can be used to estimate the minimum Post Mortem Interval (mPMI) at both indoor and outdoor crime scenes. The arthropod community discovered on a corpse or around it is affected by extrinsic and intrinsic factors [1]. The geographical area, the season and the habitat are very important in determining the composition of the faunal succession and the seasonal dynamics of insects [2,3] on exposed corpses. Knowledge of the distribution and ecological preferences of arthropod forensic indicators in a particular area [4-7] is very useful for PMI estimation and crime scene analysis. In particular, synanthropic flies, the most accurate indicators of the time of death, have been recognized on human corpses in many countries [8,9]. Until recent investigations in Calabria, southern Italy [4-7], investigators evaluating the insects collected at crime scenes in that region based their conclusions on data recorded mainly from central Europe. In the present case, five species belonging to the families Calliphoridae (Calliphora vicina Robineau-Desvoidy 1830, Lucilia sericata (Meigen 1826)), Sarcophagidae (Sarcophaga (Liopygia) crassipalpis Macquart 1839), Fanniidae (Fannia scalaris (Fabricius 1794)) and Muscidae (Hydrotaea ignava (Harris 1780)) were collected at the scene. In particular, we discussed the presence of S. crassipalpis: this is the first time the species has been collected on a corpse in Italy. mPMI was estimated on Calliphora vicina samples as discussed in the result section.

\section{Case description}

On May 24, 2013, the body of a 50-year-old male was found on the floor of a room in Cosenza (southern Italy) (Figure 1A) which did not receive direct sunlight. At the time of discovery, the door was shut but two windows of the apartment were open. The temperature in the apartment when the corpse was discovered was $22.5^{\circ} \mathrm{C}$. The cadaver was found in a supine position dressed in a shirt and trousers. The feet were completely bare. Medical evidence and a toxicological analysis carried out on the cardiac blood confirmed that death was associated with methadone intake. The methadone concentration in the blood was $242 \mathrm{ng} / \mathrm{ml}$. The body was in an advanced state of decay, with heavy maggot infestation on the face (Figure 1B) and on the entire body. Entomological evidence was abundant and present on and around the body. The procedures for collecting and processing the entomological evidence followed normal standards and guidelines [10,11]. At the autopsy on 25 May, the corpse showed general brownish discoloration and autolysis of internal organs, signs of advanced decay. Macroscopic investigations showed superficial skin lesions on the wrists, fluid and dark blood, plurivisceral congestion, hypertrophic chronic cholecystitis with cholesterolosis. Microscopic 
investigations of the lungs showed widespread spill, areas with alveolar spaces occupied by eosinophilic edema, red blood cells and polymorph nuclear leucocytes, and areas of emphysema. The heart showed several areas of coagulative necrosis with myofibrillar suffering. The brain showed hydrophic hypoxic degeneration and the liver showed chronic active hepatitis.
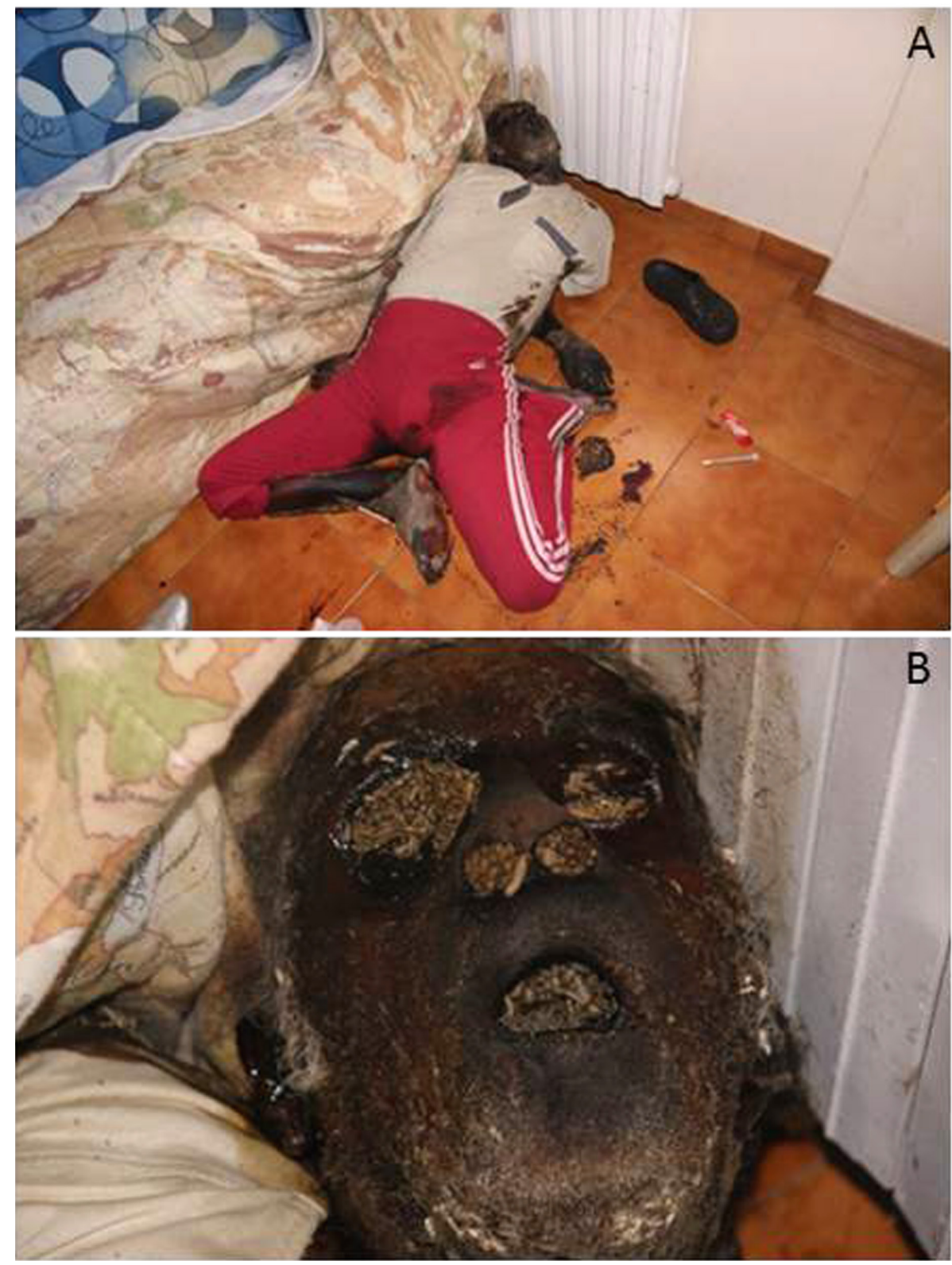

Figure 1: A. View of the room where the corpse was discovered

B. Maggots at different life stage inside the natural orifices

\section{Results}

Several dead adult specimens of Calliphora vicina Robineau-Desvoidy, 1830, Lucilia sericata (Meigen, 1826), Fannia scalaris (Fabricius 1794) and Hydrotaea ignava (Harris 1780) were found and collected around the corpse and in the bathroom next to the room with the corpse. Many maggots were observed and collected on the corpse (in the clothing, nose, mouth, eyes, ears) and around it. Sixty larvae (45 third instar larvae of C. vicina and 15 second and third instar larvae of L. sericata) were isolated and stored in $80 \%$ ethanol, while 30 larvae of C. vicina and 10 larvae of L. sericata were reared in the laboratory to the adult stage. The adults and larvae were identified using identification keys [12-17]. The larvae were killed by immersion in actively boiling water for $60 \mathrm{~s}$ and transferred to $80 \%$ ethanol for preservation [18]. Both the larvae and the adults were identified as C. vicina and L. sericata. From the sample reared in laboratory are not emerged adults of F. scalaris and H. ignava. In total, 50 third instar larvae of Sarcophaga (Liopygia) crassipalpis Macquart 1839 were collected on the body, although adults of this species were not found at scene. Thirty of these larvae were killed by immersion in actively boiling water for $60 \mathrm{~s}$ and transferred to $80 \%$ ethanol for preservation [18], while the other 20 larvae were reared in the laboratory to the adult stage at $20 \pm 0.5^{\circ} \mathrm{C}$. Both the larvae and adults were identified as $S$. 
crassipalpis (Figure 2) using identification keys [14]. All the examined larvae are deposited in the 'Tullia Zetto larval collection' (TZC) while the adults are deposited in the collection of Prof. Pietro Brandmayr (PBC) (both DiBEST Department, University of Calabria, Cosenza, Italy). Digital photographs of cadaver were taken with a Sony Super Steadyshot DSC-H2 digital camera. The larvae and adults of species were photographed with a Zeiss Axioskop equipped with Nomarski optic (Differential Interference Contrast, DIC), using a Nikon Coolpix 4500 four MP digital camera.
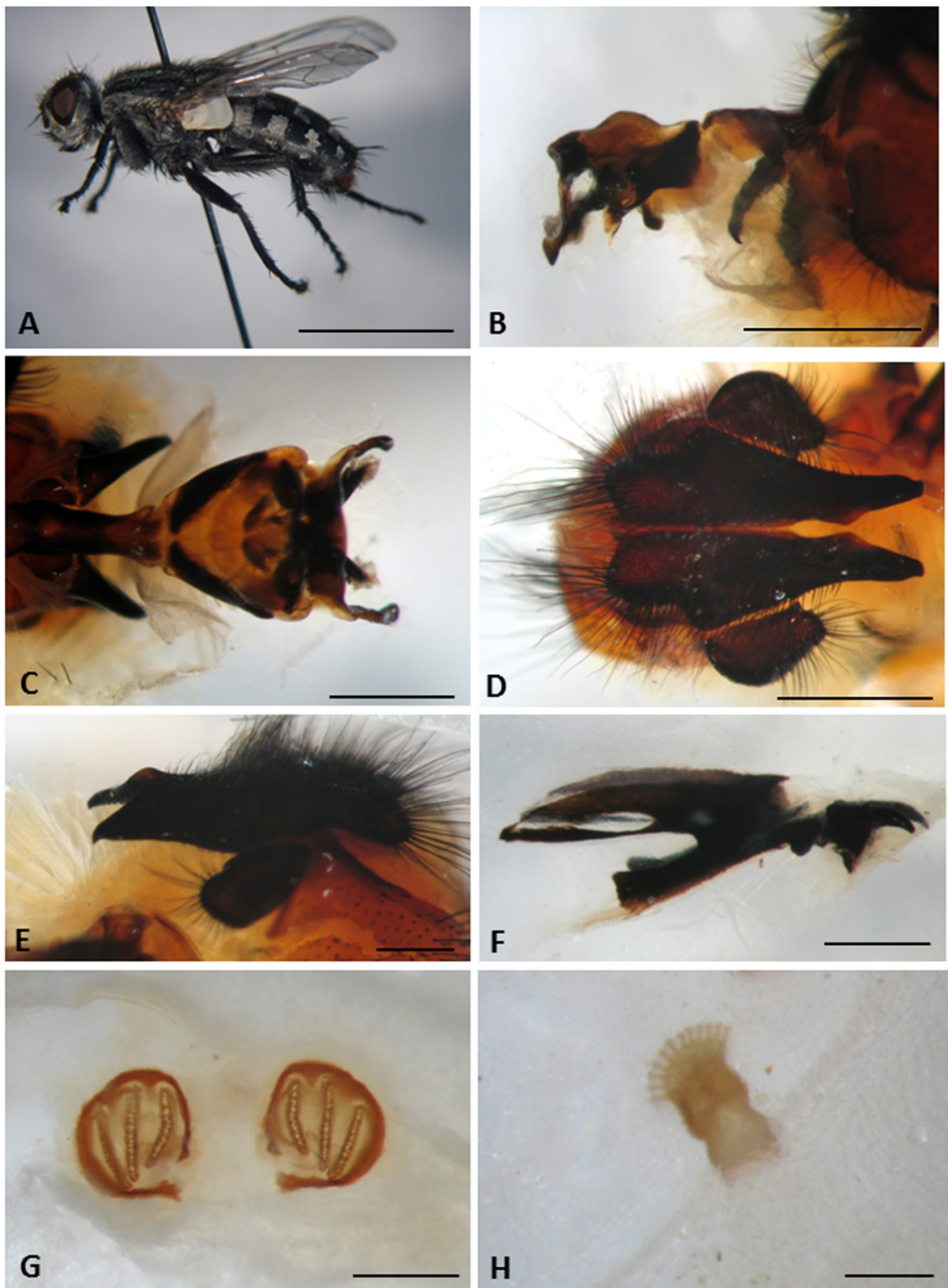

Figure 2: Sarcophaga (Liopygia) crassipalpis Macquart 1839.

A. Habitus of male (scale bar: $1 \mathrm{~cm}$ ).

B. Male genitalia, lateral view (scale bar: $1 \mathrm{~mm}$ ).

C. Male genitalia, dorsal view (scale bar: $1 \mathrm{~mm}$ ).

D. Cercus and surstylus in frontal view (scale bar: $1 \mathrm{~mm}$ ).

E. Cercus and surstylus in lateral view (scale bar: $1 \mathrm{~mm}$ ).

F. Cephalopharyngeal skeleton of third instar larva (scale bar: $0.5 \mathrm{~mm}$ ).

G. Posterior spiracles of third instar larva (scale bar: $0.25 \mathrm{~mm}$ ).

$\mathrm{H}$. Anterior spiracles of third instar larva (scale bar: $0.15 \mathrm{~mm}$ ).

Soft and clear pupae of Calliphora vicina were collected on the blanket covering the sofa, under the sofa (Figure 1A) and near the body. In this case, C. vicina pupae were used for mPMI estimation. Empty puparia were not found at the scene. In order to verify the differences between the temperature at scene and from weather stations we used an Escort Junior data logger which recorded in the apartment the temperature at 30-min intervals for 5 days after discovery of the body. Temperature data for the 10 days before discovery of the corpse were obtained from the local weather stations of the Arpacal Agency of Calabria situated 800 meters from the scene. To determine the mPMI, we used the temperatures (Min and Max) recorded before discovery of the body. The mean environmental temperature recorded during the 10 days before discovery was $21.5 \pm 1.1^{\circ} \mathrm{C}$. Laboratory evaluation aimed to study the growth of $C$. vicina larvae which fed on meat with added methadone not allow general statements concerning the determination of 
the age of larvae which developed under the influence of methadone and the effective influence of substance on the development time of the blow fly [19]. According to Marchenko [20] and unpublished data from our laboratory, the mean minimal development time from egg to pupal age of C. vicina at $22^{\circ} \mathrm{C}$ is $9.6 \pm 0.2$ days; the average minimal development time from egg to pupal age of C. vicina at $23^{\circ} \mathrm{C}$ is $9.1 \pm 0.2$ days. Based on the time of development (egg-pupal age) determined at $22^{\circ} \mathrm{C}$ for this species under laboratory conditions [20], the expected accumulated degree-day (Exp. ADD) was 192. Based on the time of development (eggpupal age) determined at $23{ }^{\circ} \mathrm{C}$, the expected accumulated degree-day (Exp. ADD) was 191. For C. vicina a lower threshold of $2{ }^{\circ} \mathrm{C}$ was applied [20]. This lower threshold is in accordance with our laboratory experimental data (unpublished data) for C. vicina. Therefore, it was estimated that oviposition of C. vicina took place somewhere between 14 and 15 May.

\section{Conclusion}

In recent years there has been a progressive increase in mortality rates from acute methadone poisoning. This can be related to the increasing diffusion of recovery programs, particularly those entrusting the methadone administration directly to the user. This practice involves the likelihood of mistakes of self-administration by patients, i.e. too high doses or methadone combined with other central nervous system depressants. In extreme cases, methadone can be used to commit suicide [21]. With regard to necrophagous fauna, many authors have reported that the number of Diptera species colonizing cadavers in domestic environments is lower than outdoors [22]. Our investigation of an indoor scene in the city of Cosenza revealed a massive colonization by flies. In fact, we collected five necrophagous Diptera species from and around the body. In Calabria, Calliphora vicina and Lucilia sericata are the most abundant synanthropic species [7]. C. vicina is active in Calabria in spring, autumn and winter, while L. sericata is active in spring and summer [7]. Hydrotaea ignava is known to be associated with carcasses in spring and summer in other geographical areas [23] and in Cosenza province [5,6]. Fannia scalaris is associated with human corpses and frequently indicates the presence of feces and urine in indoor environments [24]. In Calabria this species was reported from pig carcasses in spring and summer [5]. The presence at the scene of the flesh fly S. crassipalpis (Figure 2) is interesting. This species has been reported to cause myiasis in humans and animals (oral, intestinal, cutaneous and ophthalmic myiasis) [25-28] and has successfully been reared from pork liver [29]. This fly is known to complete larval development in vertebrate and invertebrate carcasses [30-32]. S. crassipalpis has been reared not only from dead vertebrates but also from dead invertebrates, particularly snails [33]. Adults feed on feces, carrion and flowers. This fly is defined as a hemisynanthropic species, present in tropical and subtropical zones of all biogeographical regions [33] and widely distributed in Spain, where it has also been observed associated with corpses [29,35,36]. S. crassipalpis is also abundant in Portugal, with a clear preference for sunny sites [24]. Our finding is the first report of S. crassipalpis associated with a human corpse at an indoor scene in Italy. In Calabria, S. crassipalpis shows synanthropic preferences and can also be associated with corpses located in shady conditions contrary to what has been observed in other geographical areas [24].

The large number of species collected on the body and at the scene, related to the season and the geographical area, underline the importance of evaluating entomological evidence on a regional scale. The massive presence of $S$. crassipalpis strongly suggests that the species can be considered a forensically relevant fly for indoor scenes in Calabria, like the other species (Calliphora vicina, Lucilia sericata and Chrysomya albiceps) [4-6]. These species can be defined as early colonizers and are of potential use for the estimation of $\mathrm{mPMI}$ in southern Italy.

\section{Acknowledgements}

We authors sincerely thank the Comando Provinciale Carabinieri of Cosenza for the support to this study. We thank Dr. Daniel Whitmore (Curator (Diptera) - Department of Life Sciences Natural History Museum, London) for confirming our identification of the specimens of Sarcophaga crassipalpis. Thanks to anonymous reviewers for their critical review of the manuscript.

\section{References}

1. Campobasso CP, Di Vella G, Introna F (2001) Factors affecting decomposition and Diptera colonization. Forensic Sci Int 120: $18-27$.

2. Schroeder H, Klotzbach H, Püschel K (2003) Insect's colonization of human corpses in a warm and cold season. Leg Med 5: S372-4.

3. Anderson GS (2009) Factors that influence insect succession on carrion. Forensic entomology: The utility of Arthropods in legal investigations (2nd edn), Byrd JH and Castner JL, CRC Press, Florida, United States.

4. Bonacci T, Vercillo V, Brandmayr P, Fonti A, Tersaruolo C, et al. (2009) A case of Calliphora vicina Robineau-Desvoidy, 1830 (Diptera, Calliphoridae) breeding in a human corpse in Calabria (southern Italy). Leg Med: 11: 30-2

5. Bonacci T, Brandmayr P, Greco S, Tersaruolo C, Vercillo V, et al. (2010) A preliminary investigation of insect succession on carrion in Calabria (southern Italy). Terr Arthropod Rev 3: 97-110.

6. Bonacci T, Zetto Brandmayr T, Brandmayr P, Vercillo V, Porcelli F (2011) Successional patterns of the insect fauna on a pig carcass in southern Italy and the role of Crematogaster scutellaris (Hymenoptera, Formicidae) as a carrion invaders. Entomological Science 14: 125-32.

7. Greco S, Brandmayr P, Bonacci T (in press) Synanthropy and temporal variability of Calliphoridae living in Cosenza (Calabria, South Italy). Journal of Insect Science (in press). 
8. Nuorteva P (1977) Sarcosaprophagous insects as forensic indicators. Forensic Medicine: A Study in Trauma and Environmental Hazards, Vol. II: Physical Trauma, eds. Tedeschi, et al., W. B. Saunders Co., Philadelphia, London, Toronto.

9. Smith KVG (1986) A manual of forensic entomology. The Trustees of the British Museum (Natural History), Cornell University Press, London, Ithaca.

10. Haskell NH, Catts EP (1990) Entomology and Death: A procedural guide, Joyce's Print Shop, Clemson, SC: 52-97.

11. Amendt J, Campobasso CP, Gaudry E, Reiter C, LeBlanc HN, et al. (2007) Best practice in forensic entomology-standards and guidelines. Int J Legal Med 121: 90-104.

12. Whitworth (2010) Keys to the genera and species of blow flies (Diptera: Calliphoridae) of the West Indies and description of a new species of Lucilia RobineauDesvoidy. Zootaxa 2663: 1-35.

13. Szpila K (2010) Key for the identification of third instars of European Blowflies (Diptera: Calliphoridae) of forensic importance. Current Concepts in Forensic Entomology, edited by Amendt et al., Springer Science+Business Media.

14. Richet R, Blackith RM, Pape T (2011) Sarcophaga of France (Diptera: Sarcophagidae). Pensoft, Sofia_Moscow: 327.

15. Pape T (1987) The Sarcophagidae (Diptera) of Fennoscandia and Denmark. Fauna Entomol Scand 19: 1-203.

16. Pape T (1996) Catalogue of the Sarcophagidae of the world (Insecta: Diptera). Mem Entomol Int 8: 1-558.

17. Gregor F, Rozkošný R, Barták M, Vaňhara J (2002) The Muscidae (Diptera) of Central Europe. Folia Facultatis Scientiarum Naturalium Universitatis Masarykianae Brunensis, Biologia 107: 1-280

18. Adams ZJO, Hall MJR (2003) Methods used for the killing and preservation of blowfly larvae, and their effect on post-mortem larval length. Forensic Sci Int 138: 50-61.

19. Strehler M, Klotzbach H, Madea B, Relbe S (2008) Development of Calliphora vicina under food addition of methadone. Legal Medicine 18: 425-30.

20. Marchenko MI (2001) Medicolegal relevance of cadaver entomofauna for the determination of the time of death. Forensic Sci Int 120: 89-109.

21. Tennant F (2007) Methadone deaths and warnings. Practical pain management 7: 8-9.

22. Anderson GS, VanLaerhoven SL (1996) Initial studies on insect succession on carrion in southwestern British Columbia. J Forensic Sci 41 : $617-25$.

23. Schröder H, Klotzbach H, Oesterhelweg L, Gehl A, Püschel K (2001) spectrum of species and temporal occurrence of insects flats corpses in the Hamburg area. Legal Medicine 11: 59-63.

24. Prado e Castro C, Garcia MD, Arnolds MI, González-Mora D (2010) Sarcophagidae (Diptera) attracted to piglet carcasses including new records for Portuguese fauna. Graellsia 66: 285-94

25. Benecke M (2004) Forensic entomology: Arthropods and Corpses. Forensic Path Rev Vol II, Tsokos M, Humana Press, Totowa, New Jersey, USA.

26. Morris B (1987) First reported case of human aural myiasis caused by the flesh fly Parasarcophaga crassipalpis (Diptera: Sarcophagidae). J Parasitology 73: 1068-9.

27. Shiota T, Yoshida Y, Hirai S Torii S (1990) Intestinal myiasis caused by Parasarcophaga crassipalpis (Dipera: Sarcophagidae). Pediatrics 85: $215-7$.

28. Shinonaga S, Kurahashi H (1969) New species of Sarcosolomonia Baranov from New Guinea and the Solomons (Diptera: Sarcophagidae). Pacific Insects 11: 755-61.

29. Martínez-Sánchez A, Magaña C, Pérez-Bañón C, Rojo S, González-Mora D (2006) Taxonomy and larval study of flesh flies (Diptera: Sarcophagidae) associated with human corpses in Spain. Proceedings of the Fourth Meeting of European Association for Forensic Entomology, Bari: 63 [abstract].

30. Sanjean J (1957) Taxonomic studies of Sarcophaga larvae of New York with notes on the adults. Cornell University Agricultural Experiment Station Memoir 349: 1-115.

31. Oliva A (2001) Insects of forensic significance in Argentina. Forensic Sci Int 120: 145-54.

32. Centeno N, Maldonado M, Oliva A (2002) Seasonal patterns of arthropods occurring on sheltered and unsheltered pig carcasses in Buenos Aires province (Argentina). Forensic Sci Int 126: 63-70.

33. Pérez-Moreno S, Marcos-García MA, Rojo S (2006) Comparative morphology of early stages of two Mediterranean Sarcophaga Meigen, 1826 (Diptera; Sarcophagidae) and a review of the feeding habits of Palaearctic species. Micron 37: 169-79.

34. Povolny' D, Verves YG (1997) The flesh-flies of Central Europe (Insecta, Diptera, Sarcophagidae). Spixiana Supplement 24, Munich, Germany.

35. Miralbes Castillo M (2002) Study of the insect fauna associated with carcasses in the Alto Aragón (Spain). Monographs of the Entomological Society Aragonese 6: $1-94$.

36. Romera E, Arnaldos MI, García MD, González-Mora D (2003) Los Sarcophagidae (Insecta, Diptera) de un ecosistema cadavérico en el sureste de la Península Ibérica. Anales de Biología 25: 49-63.

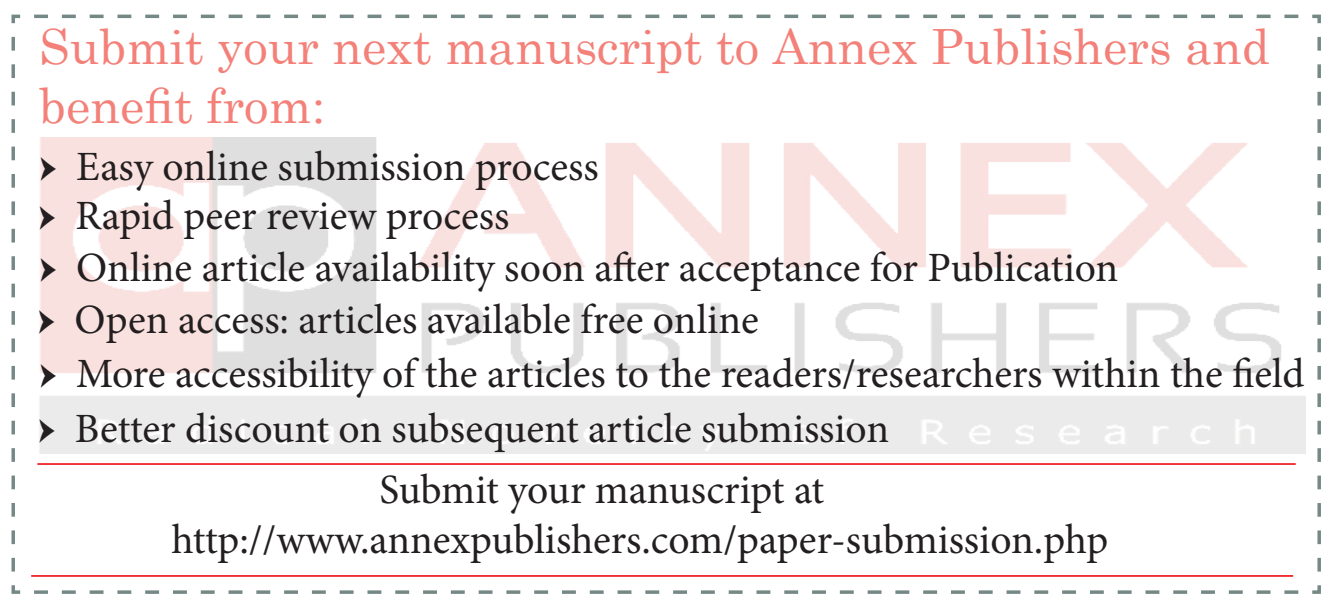

Annex Publishers | www.annexpublishers.com

Volume 2 | Issue 1 